\title{
Analytical Quality by Design Approach of Reverse-Phase High-Performance Liquid Chromatography of Atorvastatin: Method Development, Optimization, Validation, and the Stability-Indicated Method
}

\author{
Nabil K. Alruwaili (iD \\ Department of Pharmaceutics, College of Pharmacy, Jouf University, Aljouf, Sakakah, Saudi Arabia \\ Correspondence should be addressed to Nabil K. Alruwaili; nkalruwaili@ju.edu.sa
}

Received 12 September 2020; Revised 29 December 2020; Accepted 27 January 2021; Published 13 February 2021

Academic Editor: Günther K. Bonn

Copyright ( 92021 Nabil K. Alruwaili. This is an open access article distributed under the Creative Commons Attribution License, which permits unrestricted use, distribution, and reproduction in any medium, provided the original work is properly cited.

\begin{abstract}
The use of analytical quality by design (AQbD) approach in the optimization of the high-performance liquid chromatography (RP-HPLC) method is a novel tool. Three factors and three levels of Box-Behnken statistical design (BBD) were used for method optimization and analysis of atorvastatin. The mobile phase (acetonitrile: water), flow rate (Rt), and UV wavelength were used as independent variables. Their effects were observed in the area of the chromatogram (AU), retention time (Rt, min), and tailing factor (\%). The optimized HPLC condition was found as acetonitrile:water (50:50), flow rate $(0.68 \mathrm{ml} / \mathrm{min})$, and UV wave length $(235 \mathrm{~nm})$. It gives the retention time of $2.43 \mathrm{~min}$ with the linearity range of $5-30 \mu \mathrm{g} / \mathrm{ml}$ with a high regression value $\left(r^{2}=0.999\right)$. The method was found to be precise and accurate with low $\%$ RSD $(<5 \%)$. The refrigeration stability indicated that atorvastatin was stable. The force degradation study showed that the atorvastatin was fully unstable in UV light and stable in $0.1 \mathrm{M}$ basic condition. It concluded that this QbD optimized method is suitable for quantification of the atorvastatin from the formulation as well as pharmacokinetic parameters.
\end{abstract}

\section{Introduction}

Atorvastatin (ATS) belongs to statin class and is used for lowering the lipid in the body through desensitizing the making of cholesterol in the liver resulting in decreasing the risk of cardiovascular diseases. Mainly, it completely inhibited hydroxymethylglutaryl coenzyme A reductase enzyme $[1,2]$. Chemically, it is (3R, 5R)-7-[2-(4-flurophenyl)-3-phenyl-4(phenylcarbamoyl)-5-propane-2-ylpyrrol-1-yl]-3,5 dihydroxy eptanoic acid [3] (Figure 1). ATS is insoluble in water and soluble in acetonitrile, methanol, ethanol, dimethyl sulfoxide, and other organic solvents $[4,5]$.

The RP-HPLC is a very sensitive analytical technique for estimation of the drug from the formulation as well as a biological sample [6]. Some HPLC methods for ATS literature have been reported earlier by a researcher, i.e., simultaneous estimation of ATS, amlodipine, and benazepril
$[7,8]$. Erturk et al. reported the HPLC method for estimation of ATS from the bulk drug and tablet $[9,10]$. Martins and associates estimated the ATS from the biological sample [11], but ATS did not well resolve and has longer retention time (Rt).

Several published studies reported the relevance of quality by design approach for optimization of the HPLC method and provide prized information about the interaction effect of the variable over the response as well as give appropriated chromatographic condition in which drug is well separated $[12,13]$. The analytical quality by design $(\mathrm{AQbD})$ is a novel tool for optimization of HPLC instrumental conditions such as flow rate, the solvent system, solvent ratio, the effect of temperature, injection volume, the resolution of the drug (Rt) as well as cost and effort. The $\mathrm{AQbD}$ gives information on risk associated with the method as well as the influencing factor effect on analytical method 


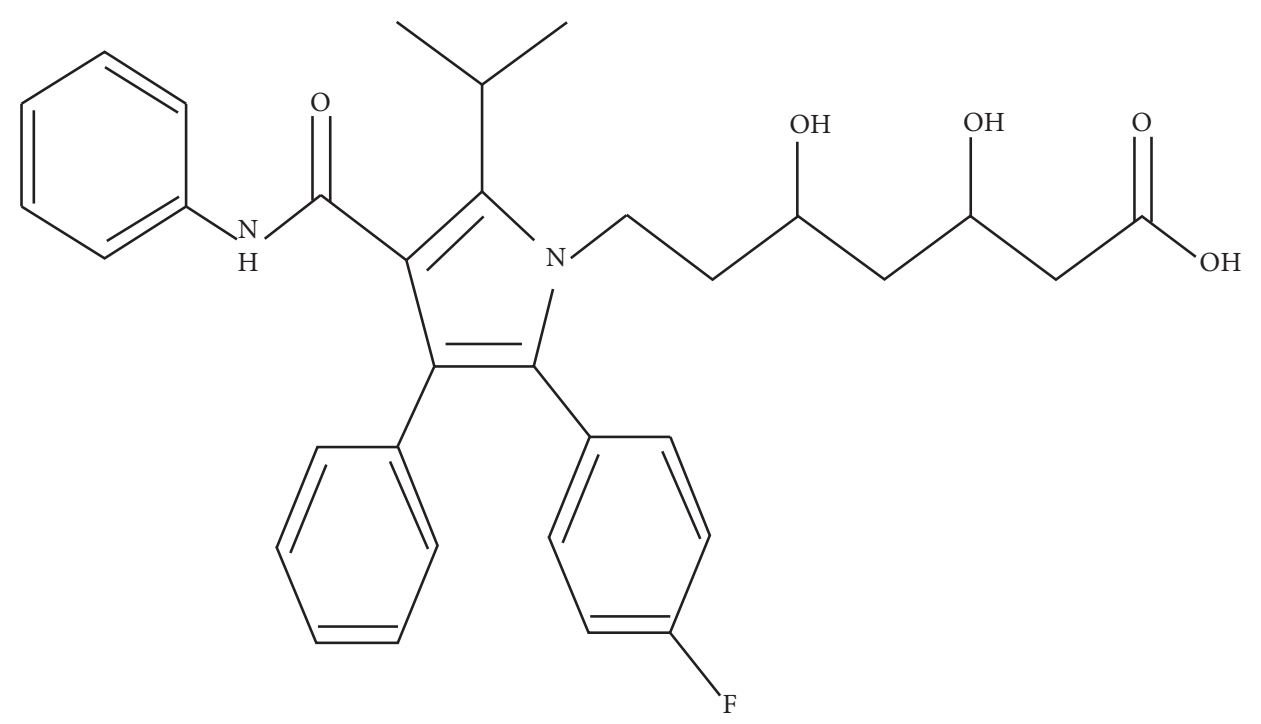

FIgURE 1: Chemical structure of atorvastatin.

performance. Various research publications have been explained by the application of AQbD approaches [14-16]. This approach can create various analytical chromatographic conditions with noticeably improved method presentation. This approach also helps in determining the crucial method variables, which directly impact the performance, enlarge the least resources of time, endeavour, and cost. It helps to understand the risk assessment of the critical factors which are directly influenced in the presentation of the analytical method $[17,18]$. It is based on the principles of experimental design that participated in a systematic thoughtful of the reasonable risk and interaction between the experimental variables [19]. The Box-Behnken design has various advantages such as prevent the waste of solvent and time. It gives a lesser number of runs in the various compositions of independent variables. There are many published research works on optimization of RP-HPLC using QbD (Box-Behnken design) reported such as voriconazole [20], methotrexate [21], dapagliflozin [12], lacidipine [13], timolol maleate [22], risperidone [23], and temozolomide [24]. No method has been reported on the RP-HPLC method using a $\mathrm{QbD}$ approach for atorvastatin. This research work developed and optimized the analytical condition by using AQbD (Box-Behnken design).

\section{Materials and Methods}

2.1. Materials. Atorvastatin (ATS, 99.99\%) as a gift sample was obtained from Aldrich (St. Louis, US). HPLC grade water, methanol, and acetonitrile were procured from Sigma Aldrich (St. Louis, US). All other chemicals used in this study are analytical grade.

\subsection{Methods}

2.2.1. Liquid Chromatographic Condition. High-performance liquid chromatography (HPLC, Auto sampler, Shimadzu LC10AD, Kyoto Japan) attached with a UV detector (SPD20A) was used for the method development of ATS. The ultrafine particle packed $250 \mathrm{~mm}$ length $\mathrm{C}_{18}$ column (Acclaim120C18, $4.6 \mathrm{~mm}$ internal diameter, $2.2 \mu \mathrm{m}$ particle size) was used for chromatographic separation of ATS. Flow range, i.e., $0.1-1 \mathrm{ml} / \mathrm{min}$, was used for separation of ATS. The different mobile phase compositions of acetonitrile and water $(50: 50,60: 40$, and $70: 30)$ were used as mobile phase. The whole operation was carried out at room temperature. The sample $(30 \mu \mathrm{L})$ was applied as injection volume for each sample.

2.2.2. Risk Assessment Study. This study was conducted to understand the various factors affecting the target quality profile (TQP). The critical analytical attributes were applied to visualize the proper relationships between parameters to the target quality profile before risk judgment. This study was used to classify the possible causes of difficulty to obtain the reason for deficiency, discrepancy, and failure (defect). It is also applied to determine the considerable role for the extraction of vital detail required to achieve the target quality profile. The factors which influence the target response are categorized as a low, medium, and high score [25]. The seven factors were used and further divided into low, medium, and high-risk levels for screening and obtaining only a few factors. Finally, three out of seven factors were selected for the optimization of responses using experiment designs (Table 1). Using this study, the target quality profile was recognized in the form of retention time (Rt), area, and tailing factor from the independent seven variables.

2.2.3. Optimization. The AQbD method was used to analyze the effect of independent factors onto the responses. Box-Behnken design (BBD, Design Expert 8.0.7.1, Stat-Ease Inc., Write country) is used for the optimization because it gives a few numbers of experimental trials with appropriate composition [21]. The three-factor and three-level BBD were used for the optimization of an analytical method. The mobile phases, i.e., acetonitrile $\left(\mathrm{X}_{1}, \%\right)$, flow rate $\left(\mathrm{X}_{2}, \mathrm{ml} / \mathrm{min}\right)$, and 
TABLE 1: RP-HPLC analytical method risk assessment for atorvastatin.

\begin{tabular}{lcccccccc}
\hline $\begin{array}{l}\text { Critical attributes } \\
\text { response }\end{array}$ & $\begin{array}{c}\text { Various RP-HPLC chromatographic conditions for atorvastatin } \\
\text { Composition of } \\
\text { mobile phase }\end{array}$ & $\begin{array}{c}\text { UV } \\
\text { wavelength }\end{array}$ & $\begin{array}{c}\text { Injection } \\
\text { volume }\end{array}$ & $\begin{array}{c}\text { Column } \\
\text { temperature }\end{array}$ & $\begin{array}{c}\text { Flow } \\
\text { rate }\end{array}$ & $\begin{array}{c}\text { Sample } \\
\text { temperature }\end{array}$ & $\begin{array}{c}\text { Column } \\
\text { dimension }\end{array}$ & $\begin{array}{c}\text { Type of } \\
\text { vial }\end{array}$ \\
\hline $\begin{array}{l}\text { Chromatogram } \\
\text { area }\end{array}$ & +2 & +1 & -1 & -1 & +2 & -1 & +1 & -1 \\
$\begin{array}{l}\text { Retention time } \\
\text { Tailing factor }\end{array}$ & +2 & +1 & -1 & +1 & +2 & -1 & +1 & -1 \\
\hline
\end{tabular}

+2 , high-risk parameter; +1 , medium-risk parameter; -1 , low-risk parameter.

UV wavelength $\left(\mathrm{X}_{3}\right)$ and their single and combined effects were examined over the selected responses, i.e., area $\left(\mathrm{Y}_{1}\right), \mathrm{Rt}$ ( $\left.\min , \mathrm{Y}_{2}\right)$, and tailing factor $\left(\%, \mathrm{Y}_{3}\right)$. In total, 17 experimental runs at various compositions were obtained from software to find out the best composition (Table 2). The experimental data were fitted into different kinetic models such as linear, second-order, quadratic, and cubic models to find the best fit model. The polynomial equation, 3D plot, and contour plot were measured to evaluate the effect of the variable on responses. Statistical analysis ANOVA and regression analysis were performed to determine the significant level for the model and to determine the best fit model.

\subsubsection{Preparation of Standard Solution and Linearity Curve.} The standard solution was prepared by weighing ATS $(10 \mathrm{mg})$ and dissolved in HPLC grade methanol $(10 \mathrm{~mL})$. From this stock solution, further dilution was performed to prepare the concentration range of $5-30 \mu \mathrm{g} / \mathrm{ml}$ using methanol. Each sample was injected $(20 \mu \mathrm{L})$ in the HPLC instrument by an autosampler, and the different parameters were determined. The linearity curve was plotted between the area of chromatogram vs. concentration $(\mu \mathrm{g} / \mathrm{ml})$, and the linear regression equation was calculated. The analysis was performed in triplicate, and the mean value with standard deviation was used.

2.2.5. Quality Control Sample. For validation of the method, the quality control sample was prepared to form a stock solution at three levels, i.e., low-quality control $(1.5 \mu \mathrm{g} / \mathrm{ml})$, the medium limit of quality control (MQC $12.43 \mu \mathrm{g} / \mathrm{ml}$ ), and high-quality control (HQC, $24 \mu \mathrm{g} / \mathrm{ml}$ ).

2.2.6. Method Validation. HPLC method was validated according to the approved protocol given in ICH Q2 (R1). The method was validated for linearity, accuracy, sensitivity, precision, recovery, LOD, and LQC of the quality control sample $[26,27]$.

2.2.7. System Suitability and Specificity. The system suitability of the method was performed, and the area, Rt, and tailing factor were assessed with the same concentration of ATS injection in six replicates. The specificity of the method was assessed to find out any interference on chromatographic separation of the ATS with a blank sample.
2.2.8. Linearity and Sensitivity Analysis. The linearity study of ATS was analyzed at a concentration range of 5-30 $\mu \mathrm{g} / \mathrm{ml}$. The prepared sample was injected into the HPLC instrument, and the peak area was noted. The linearity curve was plotted between AST concentrating vs. the peak area. The slope and regression coefficient were calculated from the curve. The study was carried out in triplicate. The limit of detection (LOD) and limit of quantification (LOQ) were analyzed by signal-to-noise ratio of $3: 1$ and 10:1 level and calculated by the following formula.

$$
\begin{aligned}
& \text { LOD }=3.3 \times \frac{\text { Standard deviation }}{\text { Slope }}, \\
& \text { LOQ }=10 \times \frac{\text { Standard deviation }}{\text { Slope }} .
\end{aligned}
$$

2.2.9. Precision and Accuracy. Accuracy and precision studies were performed to determine the closeness between several injections of the same concentration. The study was conducted several times on the same day and on different days. The intraday (within a day) and interday (different days) precision and accuracy of the method were analyzed at three different quality samples, i.e., LOC $(1.5 \mu \mathrm{g} / \mathrm{ml})$, MQC $(12.43 \mu \mathrm{g} / \mathrm{ml})$, and HQC $(24 \mu \mathrm{g} / \mathrm{ml})$ for six replicates three times a day and three different days. The regressed standard deviation (\% RSD) was calculated for each study.

2.2.10. Recovery Studies. The recovery study of ATS was estimated by spiking the sample after the addition of an extra quantity of standard ATS (50, 100, and 150\%). The analysis was performed by HPLC using an optimized mobile phase, flow rate, and UV wavelength in triplicate. The \% recovery was calculated by the given formula:

$$
\% \text { Recovery }=\frac{\text { Recovered concentration }}{\text { Initial concentration }} \times 100 \text {. }
$$

2.2.11. Storage Stability Study. The refrigerated stability of ATS was analyzed at LQC and HQC concentration. The study was conducted at different temperatures for longterm, bench-top, freeze-thaw, and postprocessing stability. The long-term ATS stability was performed at $-80^{\circ} \mathrm{C}$ for 30 days in the deep freezer. The freeze-thaw ATS stability was performed at $-20^{\circ} \mathrm{C}$ to $25^{\circ} \mathrm{C}$ for three successive days. The bench-top study was carried out at $25^{\circ} \mathrm{C}$ after $24 \mathrm{~h}$ of storage. 
TABLE 2: Critical influencing variable and their actual and predicted values of responses.

\begin{tabular}{|c|c|c|c|c|c|c|c|c|c|}
\hline \multirow{3}{*}{$\begin{array}{l}\text { Standard } \\
\text { order }\end{array}$} & \multicolumn{3}{|c|}{ Critical influencing variable } & \multicolumn{6}{|c|}{ Response } \\
\hline & \multirow{2}{*}{$\begin{array}{c}\text { Acetonitrile } \\
(\%)\end{array}$} & \multirow{2}{*}{$\begin{array}{l}\text { Flow rate } \\
(\mathrm{ml} / \mathrm{min})\end{array}$} & \multirow{2}{*}{$\begin{array}{c}\text { Wavelength } \\
(\mathrm{nm})\end{array}$} & \multicolumn{2}{|c|}{ Area (AU) } & \multicolumn{2}{|c|}{ Retention time } & \multicolumn{2}{|c|}{ Tailing factor } \\
\hline & & & & $\begin{array}{l}\text { Actual } \\
\text { value }\end{array}$ & $\begin{array}{l}\text { Predicted } \\
\text { value }\end{array}$ & $\begin{array}{l}\text { Actual } \\
\text { value }\end{array}$ & $\begin{array}{l}\text { Predicted } \\
\text { value }\end{array}$ & $\begin{array}{l}\text { Actual } \\
\text { value }\end{array}$ & $\begin{array}{l}\text { Predicted } \\
\text { value }\end{array}$ \\
\hline 1 & 50 & 0.35 & 240 & 1975990 & 1975589 & 2.19 & 2.18 & 1.95 & 1.94 \\
\hline 2 & 90 & 0.35 & 240 & 1501486 & 1502578 & 4.18 & 4.19 & 2.42 & 2.41 \\
\hline 3 & 50 & 1 & 240 & 2149670 & 2148578 & 3.23 & 3.22 & 2.12 & 2.12 \\
\hline 4 & 90 & 1 & 240 & 1730395 & 1730796 & 5.33 & 5.34 & 2.47 & 2.48 \\
\hline 5 & 50 & 0.68 & 235 & 2037161 & 2038807 & 2.45 & 2.47 & 2.08 & 2.09 \\
\hline 6 & 90 & 0.68 & 235 & 1565069 & 1565223 & 4.84 & 4.84 & 2.51 & 2.52 \\
\hline 7 & 50 & 0.68 & 245 & 2004970 & 2004816 & 2.83 & 2.83 & 2.04 & 2.05 \\
\hline 8 & 90 & 0.68 & 245 & 1589253 & 1587607 & 4.62 & 4.6 & 2.44 & 2.43 \\
\hline 9 & 70 & 0.35 & 235 & 1755465 & 1754220 & 2.9 & 2.89 & 2.21 & 2.21 \\
\hline 10 & 70 & 1 & 235 & 1984765 & 1984211 & 4.02 & 4.02 & 2.34 & 2.33 \\
\hline 11 & 70 & 0.35 & 245 & 1777250 & 1777804 & 2.98 & 2.99 & 2.14 & 2.15 \\
\hline 12 & 70 & 1 & 245 & 1947774 & 1949019 & 4.04 & 4.05 & 2.26 & 2.26 \\
\hline 13 & 70 & 0.68 & 240 & 1804782 & 1804782 & 3.54 & 3.54 & 2.01 & 2.01 \\
\hline 14 & 70 & 0.68 & 240 & 1804782 & 1804782 & 3.54 & 3.54 & 2.02 & 2.01 \\
\hline 15 & 70 & 0.68 & 240 & 1804782 & 1804782 & 3.54 & 3.54 & 2.01 & 2.01 \\
\hline 16 & 70 & 0.68 & 240 & 1804782 & 1804782 & 3.54 & 3.54 & 2.01 & 2.01 \\
\hline 17 & 70 & 0.68 & 240 & 1804782 & 1804782 & 3.54 & 3.54 & 2.01 & 2.01 \\
\hline
\end{tabular}

The postoperation study was carried out at $10^{\circ} \mathrm{C}$ by storing the sample in an autosampler of HPLC. The study was conducted in six replicates, and drug concentration as well as $\%$ RSD was calculated.

2.2.12. Forced Degradation Study. Stress degradation study provides information about the stability of the drug and drug product. It gives information about the stability of substances with acid, base, light, $\mathrm{pH}$, hydrolysis, and oxidation condition. It directly affects the selection of formulation development, packaging, storage, transportation, shelf life, chemical stability of the drug, and drug product $[28,29]$.

2.2.13. Acid and Base Degradation Analysis. The study was conducted with $1 \mathrm{M}$ hydrochloric acid and $0.1 \mathrm{M}$ sodium hydroxide. An equal volume ratio of the ATS stock solution was taken and added to acid and base solutions and mixed into the round bottom flask. The mixture was refluxed using an air reflux condenser at $90^{\circ} \mathrm{C}$ for $6 \mathrm{~h}$, and then, the sample was cooled at room temperature. The sample was appropriately diluted with HPLC methanol, filtered through with the membrane filter $(0.45 \mu \mathrm{m})$, and injected into the HPLC instrument.

2.2.14. Oxidation Degradation Study. The oxidation degradation study was carried out by using the oxidizing agent hydrogen peroxide $(30 \%)$. The standard stock solution of ATS was mixed with hydrogen peroxide in equal volume. The sample was refluxed with air condenser at $90^{\circ} \mathrm{C}$ for $6 \mathrm{~h}$ and cooled at room temperature, diluted with methanol. The sample $(20 \mu \mathrm{l})$ was injected into the HPLC instrument and analyzed for drug content.
2.2.15. Photolytic Degradation Study. The photodegradation study was conducted to evaluate the effect of UV light during the processing of API for formulation development. For this study, the standard stock solution of ATS placed into an open quartz glass vial and exposed with UV light (200 watt/ square meter) for $24 \mathrm{~h}$. Then, the sample was appropriately diluted with HPLC grade methanol and analyzed by HPLC.

\section{Result and Discussion}

3.1. Method Development. The RP-HPLC analytical method of ATS was developed and optimized by AQbD. The various mobile phases such as methanol, acetonitrile, water, and phosphate buffer in different compositions were used with different flow rates to obtain a suitable RP-HPLC method. Among different mobile systems with different ratios, a well-resolved peak was not found. The retention time was also found to be high. Finally, acetonitrile and water as the mobile phase was tried at 50:50 v/v and got a well-determined peak at $2.43 \mathrm{~min}$ using a flow rate of $0.5 \mathrm{ml} / \mathrm{min}$, at $235 \mathrm{~nm}$. The further mobile phase, flow rate, and UV wavelength were used to optimize BBD software for a robust method.

3.2. Risk Assessment Study. The risk assessment study was carried out for the determination of essential constraint of the method and to get the robust condition. It shows the connection between various parameters and analytical attributes. As per the examination of previously published research work descriptions, various possible input parameters were measured at a different level of risks connected with each experimental parameter of the HPLC method, i.e., the ratio of mobile phase and flow rate. It was found that wavelength and flow rate in the medium risk zone and other constraints have less risk due to the negligible effect on the 
developed method. There is continuous improvement in the design space that has been found with the use of risk management and screening, experimental design, and response surface methodology to get an optimum analytical condition. The use of the high, medium, and low-risk factors is depicted in Table 1.

3.3. Optimization. The BBD software was used for the optimization of analytical (HPLC) parameters to get the optimum conditions for the estimation of ATS. The independent variables such as acetonitrile $(50-90 \% \mathrm{v} / \mathrm{v})$, flow rate $(0.35-1 \mathrm{ml} / \mathrm{min})$, and wavelength $(235-245 \mathrm{~nm})$ were used to determine the effect on dependent variables (Rt, area, and tailing factor). Total seventeen experimental runs with five centre points obtained from the software for determination of optimum chromatographic separation of ATS (Table 2). The variables, i.e., mobile phase ratio (water: acetonitrile $30: 70 \% \mathrm{v} / \mathrm{v})$, flow rate $(0.7 \mathrm{ml} / \mathrm{min})$, and wavelength $(240 \mathrm{~nm})$, are the centre point of composition. The desirable factor was found to be very close to one (0.9653) at centre point, indicating well-fitting of the model, and the responses were within the target value. The effects of variables over the responses were evaluated to select the design space. The data of responses were fitted into different polynomial designing models such as linear, second-order, quadratic, and cubic. The quadratic model was found to be the best fit model because its regression coefficient $\left(R^{2}=0.9999\right)$ is significantly higher $(p<0.0001)$ than other models. The ANOVA of each model was evaluated, and parameters such as the sum of the square, $F$ value, mean square, and $p$ value of each response were also calculated. The $3 \mathrm{D}$ and contour plot of each response was constructed from the software and demonstrated the effect of multiple variables (integration effect) on a response at one time (Figures 2(a)-2(c)).

3.4. Effect of Independent Factors on Peak Area. The effect of an independent variable on the peak area was expressed by the $3 \mathrm{D}$ response, contour plot, and polynomial equation. The $2^{\text {nd }}$ order quadratic polynomial for response $Y_{1}$ (area) is given as follows.

Area $\quad\left(Y_{1}\right)=1804782-222698.48 X_{1}-100301.57 X_{2}-$ $2901.74 X_{3}+13807.15 X_{1} X_{2}+14093.63 X_{1} X_{3}-14694.06 X_{2} X_{3}$ $-16298.40 X_{1}^{2}+50901.77 X_{2}^{2}+10629.64 X_{3}^{2}$.

In this polynomial equation, the $X_{1}, X_{2}, X_{3}, X_{1} X_{2}, X_{1} X_{3}$, $X_{2} X_{3}, X_{1}^{2}, X_{2}^{2}$, and $X_{3}^{2}$ are the significant model terms because all the model terms have $p<0.05$. The $F$ value of the quadratic model was found to be 32195.28 , and it implies that the model is significant. The predicted $R^{2}(0.9996)$ is closer to the adjusted $R^{2}(0.9999)$. The adequate precession is greater than four (646.328), and it indicated that the model has sufficient signal. The polynomial equation showed that acetonitrile $\left(X_{1}, \mathrm{ACN}\right)$ has shown a positive effect, whereas flow rate $\left(X_{2}\right)$ and wavelength $\left(X_{3}\right)$ have a negative effect on the peak area. The peak area linearly decreases with an increase in the acetonitrile percentage with respect to water, flow rate, and wavelength (Figure 2(a)). But the percentage of acetonitrile and flow rate has a dominant effect on the peak area of chromatogram as compared to detector wavelength.

3.5. Effect of Independent Factors on Retention Time. The effect of an independent variable on the retention time was expressed by the $3 \mathrm{D}$ response, contour plot, and polynomial equation. The $2^{\text {nd }}$ order quadratic polynomial equation for the response $Y_{2}$, retention time, is given as follows.

Retention time $\left(Y_{2}\right)=+3.54+1.02 X_{1}+0.55 X_{2}+$ $0.024 X_{3}+0.027 X_{1} X_{2}-0.1 X_{1} X_{3}-0.015 X_{2} X_{3}+0.21 X_{1}^{2}-$ $0.018 X_{1}^{2}-0.037 X_{1}^{2}$.

The effects of the different variables on flow rate were expressed by the polynomial equation, $3 \mathrm{D}$ plot, and contour plots. The factors $X_{1}, X_{2}$, and $X_{3}$ showed the synergistic effect on the response. On increasing the $\%$ of acetonitrile $\left(X_{1}\right)$, the Rt of ATS increased. The high increment of Rt is not good for analysis because of the wastage of the solvent as well as time. So, it selected the medium percentage of solvent for analysis. The flow rate $\left(X_{2}\right)$ increases as the Rt value increases slightly as compared to acetonitrile. The design showed the quadratic model as the best fit model because the regression coefficient is closer to one $\left(R^{2}=0.9999\right)$ than other analytical experimental design models. The model $F$ value (5910.01) implies that the model is significant $(p<0.05)$. All the model terms $\left(X_{1}, X_{2}, X_{3}, X_{1} X_{2}, X_{1} X_{3}, X_{2} X_{3}, X_{1}^{2}, X_{2}^{2}\right.$, and $\left.X_{3}^{2}\right)$ have $p<0.05$, indicating a significant model term. The predicted $R^{2}(0.9997)$ is closer to the adjusted $R^{2}(0.9979)$. The adequate precession value from the software represented is greater than four (1923.940) and indicates that the model has sufficient signal. The 3D and contour plot showed that the Rt increases with increase in the flow rate (Figure 2(b)). In this method, the medium level of flow rate $(\mathrm{ml} / \mathrm{min})$ was selected as an optimized condition for the method development. The third-factor wavelength showed increases in the UV wavelength; the Rt value of ATS slightly increases as compared to other factors, i.e., acetonitrile and flow rate. The interaction effect (combined) of acetonitrile, wavelength $\left(X_{1} X_{3}\right)$ and flow rate, wavelength $\left(X_{2} X_{3}\right)$ showed an antagonistic effect on the Rt of ATS.

3.6. Effect of Independent Factors on Tailing Factor. The effect of an independent variable on the retention time was expressed by the $3 \mathrm{D}$ response, contour plot, and polynomial equation. The $2^{\text {nd }}$ order quadratic polynomial equation for the response $Y_{3}$ (tailing factor) is given as follows.

Tailing factor $\left(Y_{3}\right)=+2.012+0.206 X_{1}+0.059 X_{2}-$ $0.032 X_{3}-0.03 X_{1} X_{2}-0.008 X_{1} X_{3}-0.002_{3}+0.129 X_{1}^{2}+0.099$ $X_{1}^{2}+0.127 X_{3}^{2}$.

The quadratic model was found to be the best model rather than other analytical experimental designing models. The regression coefficient is found close to one $\left(R^{2}=0.9993\right)$ (Table 3). The model terms $X_{1}, X_{2}, X_{2}, X_{1} X_{2}, X_{1}^{2}, X_{2}^{2}$, and $X_{3}^{2}$ are the significant effects on response $(p<0.05)$ and other $X_{1} X_{3}$ and $X_{2} X_{3}$ are insignificant $(p>0.1)$ on response. The model $F$ value was found too high (1113.03) and implies that the model is significant. The $F$ value of lack fit was found to be less (5.42), and it indicates that the model is nonsignificant $(p>0.1)$; it is good for the fitted quadratic model. 

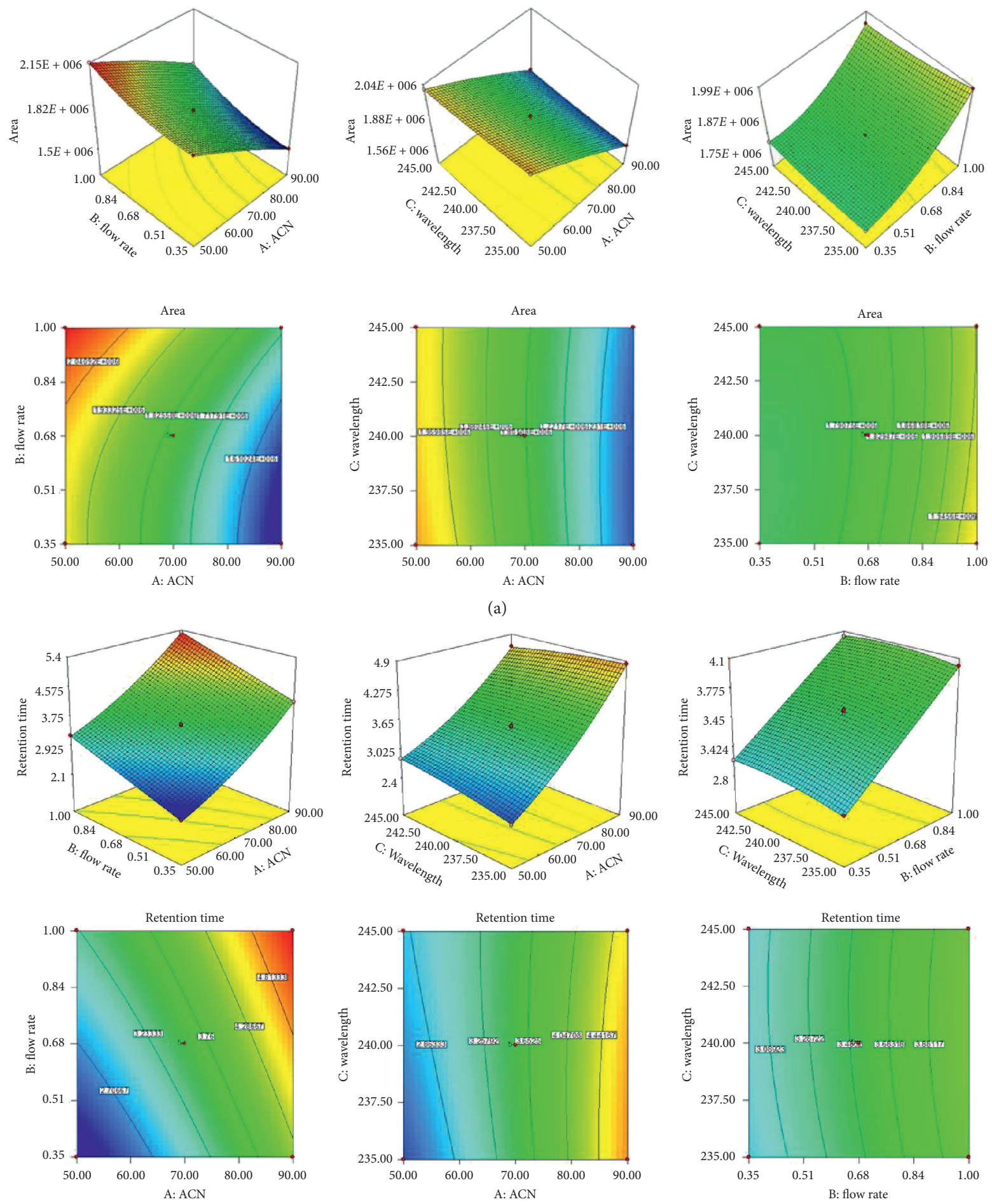

(b)

Figure 2: Continued. 

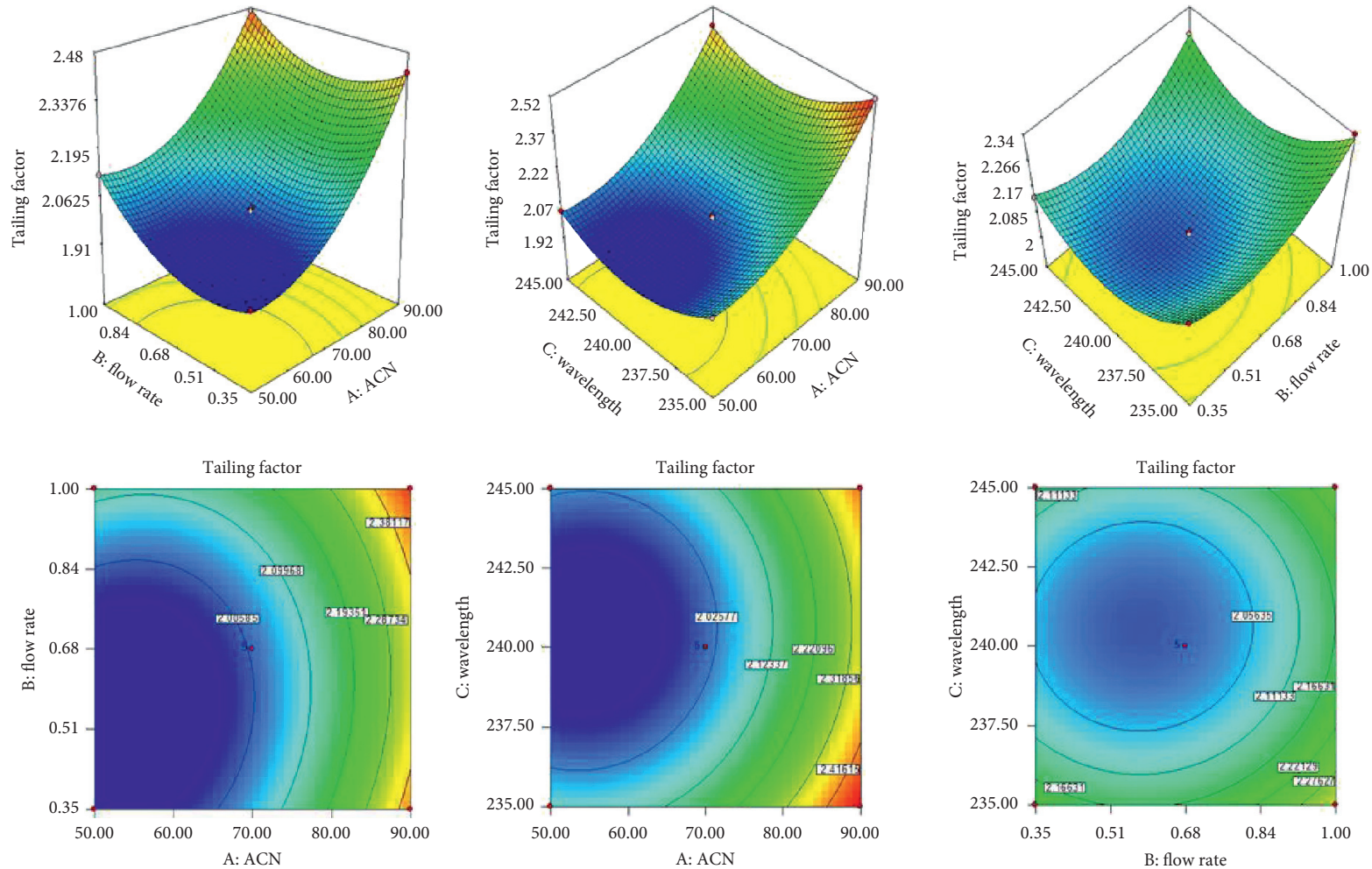

(c)

Figure 2: (a) Effect of acetonitrile, flow rate, and wavelength on the area. (b) Effect of acetonitrile, flow rate, and wavelength on the retention time. (c) Effect of acetonitrile, flow rate, and wavelength on the tailing factor.

TABle 3: Statistical ANOVA results for the responses $\left(Y_{1}=\right.$ area; $Y_{2}=$ retention time; $Y_{3}=$ tailing factor).

\begin{tabular}{|c|c|c|c|}
\hline Result (ANOVA) & Area & Retention time & Tailing factor \\
\hline \multicolumn{4}{|l|}{ Regression } \\
\hline Sum of squares & 23701247441 & 1.56 & 2.58 \\
\hline Degrees of freedom $(\mathrm{df})$ & 9 & 9 & 9 \\
\hline Mean squares & 2633471938 & 0.17 & 0.28 \\
\hline$F$ value & 253.39 & 25.40 & 199.28 \\
\hline$P$ & $<0.0001$ & 0.0002 & $<0.0001$ \\
\hline \multicolumn{4}{|l|}{ Lack of fit tests } \\
\hline Sum of squares & 55661902.75 & 0.01 & 0.004 \\
\hline Degrees of freedom $(\mathrm{df})$ & 3 & 3 & 3 \\
\hline Mean squares & 18553967.58 & 0.002 & 0.002 \\
\hline$F$ value & 4.34 & 0.16 & 0.91 \\
\hline$P$ & 0.10 & 0.92 & 0.51 \\
\hline \multicolumn{4}{|l|}{ Residual } \\
\hline Sum of squares & 72750482.75 & 0.05 & 0.01 \\
\hline Degrees of freedom $(\mathrm{df})$ & 7 & 7 & 7 \\
\hline Mean squares & 10392926.11 & 0.01 & 0.001 \\
\hline
\end{tabular}

The variable effect on the tailing factor was evaluated by the 3D surface and contour plot. It showed the mobile phase system and flow rate favoured the response, whereas detector UV wavelength has a negative response. The $3 \mathrm{D}$ and contour plot showed that increasing acetonitrile percentage $\left(X_{1}\right)$ increases the tailing factor (Figure 2(c)). The high and lesser values of the tailing factor are not suggested for the analytical method (HPLC). For this selected medium, acetonitrile concentration was found to be within the standard limit [30]. The $2^{\text {nd }}$ factor solvent flow rate $\left(X_{2}\right)$ increases; the tailing factor also increases but has a less prominent effect than factor A (Figure 2(c)). Moreover, the third-factor UV wavelength $\left(X_{3}\right)$ has a negative effect on the tailing factor, which means UV wavelength increases from $235 \mathrm{~nm}$ to $245 \mathrm{~nm}$ and the tailing factor decrease. The interaction effect of acetonitrile (A) and flow rate showed the 
negative effect on the tailing factor, and other interaction factors $\left(X_{2} X_{3}\right.$ and $\left.X_{1} X_{3}\right)$ showed no significant effect $(p>0.1)$ on the tailing factor.

3.7. Optimization by Point Prediction. The further optimization of the chromatographic condition was carried out by point prediction. The changes in the mobile phase composition, flow rate, and wavelength were carried out in the software. The optimized chromatographic condition, i.e., mobile phase (50:50\%), wavelength $235 \mathrm{~nm}$, and flow rate $0.7 \mathrm{ml} / \mathrm{min}$, shows the responses for area as $2036620 \mathrm{AU}$, retention time $2.43 \mathrm{~min}$, and tailing $2.08 \%$. It showed less error (\%) from the predicted value (software value).

\section{Validation}

4.1. System Suitability and Specificity. The system suitability of ATS was determined at different responses or critical analytical attributes, i.e., the area of the chromatogram, Rt, and tailing effect. It was found that there are no significant $(p>0.05)$ differences in responses after the evaluation of six replicates of analysis. The RSD (\%) system suitability of the method found to be $<1(0.73)$ represented the high scale of precision of instrument [31]. The specificity of the developed analytical chromatographic method was performed in the blank and spiked quality control samples, and it was found that there is no interference with blank and standard quality control samples (Figures 3(a) and 3(b)). It confirmed that the method was suitable and specific for the quantification of ATS from the formulation.

4.2. Linearity and Sensitivity Analysis. The standard curve of ATS was conducted at $5-30 \mu \mathrm{g} / \mathrm{ml}$ standard solution using optimized chromatographic conditions (Table 4). The regression coefficient $\left(R^{2}\right)$ was found to be 0.999 , and the regression equation was $98881 x+71.42$. The RSD of slope and intercept was calculated and found as $0.89 \%$ and $0.76 \%$, respectively. It was found as less than $5 \%$, and it indicates that the method was good and accurate. The limit of detection and limit of quantification was found to be $0.25 \mu \mathrm{g} /$ $\mathrm{ml}$ and $0.83 \mu \mathrm{g} / \mathrm{ml}$, respectively.

4.3. Precision and Accuracy. The precision and accuracy of the developed method at an optimized chromatographic condition in different quality control samples were analyzed in six replicates, and the data are expressed in Table 5. The percentage RSD was determined and found between 1.70 and 2.79 for intraday and 1.25 and 2.71 for interday at LQC, MQC, and HQC quality control sample. RSD was $<5 \%$, and as per the guidelines, it indicates that the method was accurate and suitable $[32,33]$. The percentage accuracy of the quality control sample (LQC, MQC, and HQC) was found to be $98.66 \pm 2.86-99.83 \pm 1.79$ for intraday and $98.33 \pm 2.46-99.91 \pm 2.33$ for interday, respectively. The accuracy of the method was found to be within the acceptable limit of the guideline.
4.4. Recovery Study. The recovery study of ATS was determined by adding an extra amount of drug into analytes. The recovery of ATS was found to be 98.66-100.26, respectively, with the low RSD (0.98-1.91\%). The low RSD $(<5 \%)$ indicates that the method was accurate.

4.5. Storage Stability Study. The refrigerated storage stability of ATS was analyzed at two levels of quality samples, i.e., LQC and HQC $(1.5 \mu \mathrm{g} / \mathrm{mL}$ and $24 \mu \mathrm{g} / \mathrm{mL})$, and the result is given in Table 6 . The percentage recovery at the LQC level was $99.33-100 \%$ and at the HQC level was $99.58-100 \%$ in different storage conditions, i.e., short-term stability $\left(25^{\circ} \mathrm{C}\right.$, $24 \mathrm{~h})$, long-term stability $\left(-80^{\circ} \mathrm{C}, 30\right.$ days $)$, freeze-thaw stability (three cycles, $-20^{\circ} \mathrm{C}$ to $25 \mathrm{C}$ ), postpreparative stability $\left(10^{\circ} \mathrm{C}, 24 \mathrm{~h}\right)$, and short-term stability $\left(25^{\circ} \mathrm{C}, 24 \mathrm{~h}\right)$. There was no significant $(p>0.05)$ change found with a low value of $\%$ RSD $(<5 \%)$. The low value of RSD indicated that ATS was stable at different freezing storage conditions.

\section{Forced Degradation Study}

5.1. Acid Degradation Study. The chromatogram of ATS after the degradation study showed one additional peak at $3.8 \mathrm{~min}$ except than the standard ATS peak (2.43 min) (Figure 4(a)). The additional peak indicated that ATS was unstable at a high molar concentration of $\mathrm{HCl}$ as well as at high temperature. As per previous work' report, the most prominent acid degradation product is lacton. The degradation product form by lactonization of 3,5-dihydroxyheptanoate side chain under mild acidic condition and further may degrade upon exposure with strong acid for long exposure time [34, 35].

5.2. Basic Degradation Study. The base degradation study was conducted in $0.1 \mathrm{M}$ sodium hydroxide, and no additional peaks were found in the chromatogram of AST (Figure 4(b)). There was $100 \%$ concentration retained, and it indicates that the drug was stable in basic condition.

5.3. Oxidative Degradation Study. An oxidation degradation study was conducted using hydrogen peroxide solution $(30 \%$ $\mathrm{v} / \mathrm{v})$ under reflex condition. One additional well-resolved peak was observed at Rt $3.54 \mathrm{~min}$ in addition to the standard ATS peak $(\mathrm{Rt}=2.43 \mathrm{~min})$ (Figure $5(\mathrm{a})$ ). The mechanism of hydrogen peroxide oxidation takes place by oxidation of pyrrole ring of ATS and may be the formation of unstable endoperoxide that takes place [36].

5.4. UV Photolytic Degradation Study. The study was carried out by placing the standard sample under UV light $(254 \mathrm{~nm})$ for $24 \mathrm{~h}$, and chromatogram is depicted in Figure 5(b). There are many ATS peaks observed in the degradation chromatogram of ATS. The degradation peaks were observed at different Rts (2.71 $\mathrm{min}, 3.16 \mathrm{~min}, 3.38 \mathrm{~min}$, and $3.7 \mathrm{~min})$. It indicates that ATS was completely degraded under UV light after long time exposure due to absorption of energy from UV light by molecules. The molecule is absorbed and indulgences the energy in presence of UV light. ATS molecule 


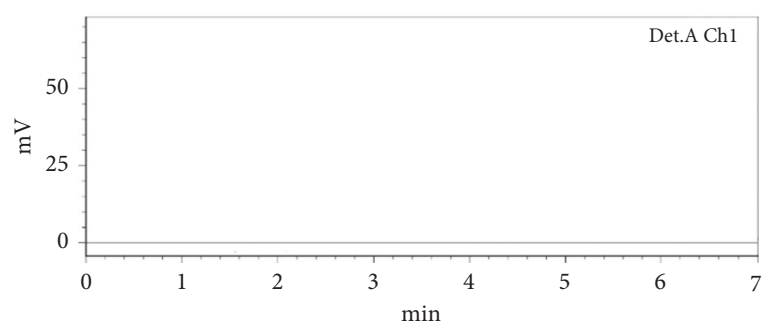

(a)

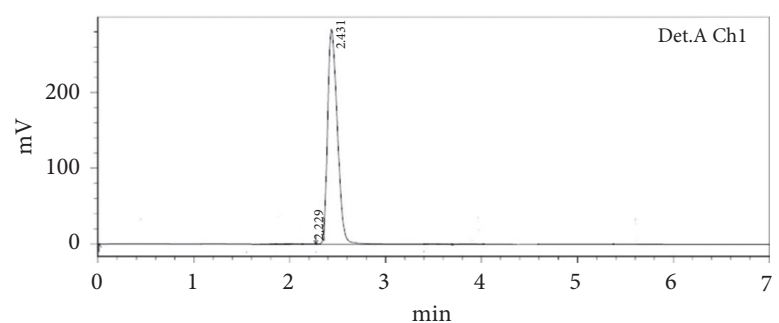

(b)

Figure 3: HPLC chromatogram of (a) blank sample and (b) atorvastatin sample.

TABLE 4: Linearity data of ATS

\begin{tabular}{lr}
\hline Parameter & Observed result \\
\hline Linearity range & $5-30 \mu \mathrm{g} / \mathrm{ml}$ \\
Calibration equation & $Y=98881 x+71.42$ \\
Slop & 98881 \\
Intercept & 71.42 \\
Limit of detection & $0.254 \mu \mathrm{g} / \mathrm{ml}$ \\
Limit of quantification & $0.838 \mu \mathrm{g} / \mathrm{ml}$ \\
\hline
\end{tabular}

TABle 5: Precision and accuracy of different quality control samples of ATS.

\begin{tabular}{lccccccc}
\hline $\begin{array}{l}\text { Quality control } \\
\text { sample }\end{array}$ & $\begin{array}{c}\text { Concentration } \\
(\mu \mathrm{g} / \mathrm{ml})\end{array}$ & \multicolumn{2}{c}{ Intraday precision and accuracy } & \multicolumn{3}{c}{ Interday precision and accuracy } \\
& $\begin{array}{c}\text { Experimental } \\
\text { concentration }\end{array}$ & $\begin{array}{c}\% \\
\text { RSD }\end{array}$ & Accuracy & $\begin{array}{c}\text { Experimental } \\
\text { concentration }\end{array}$ & RSD & Accuracy \\
\hline LQC & 1.5 & $1.48 \pm 0.04$ & 2.70 & $98.66 \pm 2.9$ & $1.475 \pm 0.04$ & 2.71 & $98.33 \pm 2.46$ \\
MQC & 12.44 & $12.42 \pm 0.3$ & 2.41 & $99.84 \pm 2.1$ & $12.43 \pm 0.3$ & 2.41 & $98.91 \pm 2.33$ \\
HQC & 24 & $23.96 \pm 0.43$ & 1.79 & $99.83 \pm 1.8$ & $23.94 \pm 0.3$ & 1.25 & $99.75 \pm 1.41$ \\
\hline
\end{tabular}

TABLE 6: Stability study of ATS at different quality controls.

\begin{tabular}{|c|c|c|c|c|}
\hline $\begin{array}{l}\text { Quality control } \\
\text { sample }\end{array}$ & Refrigerated condition and time & $\begin{array}{l}\text { Experimental } \\
\text { concentration }\end{array}$ & $\begin{array}{c}\% \text { experimental } \\
\text { drug }\end{array}$ & $\begin{array}{c}\% \\
\text { RSD } \\
\end{array}$ \\
\hline \multirow{5}{*}{ LOC $(1.5 \mu \mathrm{g} / \mathrm{ml})$} & Initial $(0 \mathrm{~h})$ & $1.5 \pm 0.02$ & 100 & 1.33 \\
\hline & Short-term storage stability $\left(25^{\circ} \mathrm{C} / 24 \mathrm{~h}\right)$ & $1.5 \pm 0.03$ & 100 & 1.33 \\
\hline & Long-term stability $\left(-80^{\circ} \mathrm{C}, 30\right.$ days $)$ & $1.49 \pm 0.03$ & 99.33 & 2.01 \\
\hline & $\begin{array}{l}\text { Three cycles freeze-thaw stability (three cycles, }-20^{\circ} \mathrm{C} \text { to } \\
\qquad 25 \mathrm{C} \text { ) }\end{array}$ & $1.48 \pm 0.02$ & 98.66 & 1.35 \\
\hline & Postpreparative stability $\left(10^{\circ} \mathrm{C}, 24 \mathrm{~h}\right)$, initial $(0 \mathrm{~h})$ & $1.49 \pm 0.03$ & 99.33 & 2.01 \\
\hline \multirow{5}{*}{ HQC $(24 \mu \mathrm{g} / \mathrm{ml})$} & Initial $(0 \mathrm{~h})$ & $24 \pm 0.2$ & 100 & 0.83 \\
\hline & Short-term stability $\left(25^{\circ} \mathrm{C}, 24 \mathrm{~h}\right)$ & $23.99 \pm 0.3$ & 99.95 & 1.25 \\
\hline & Long-term stability $\left(-80^{\circ} \mathrm{C}, 30\right.$ days $)$ & $23.90 \pm 0.3$ & 99.58 & 1.26 \\
\hline & $\begin{array}{l}\text { Three cycles freeze-thaw stability (three cycles, }-20^{\circ} \mathrm{C} \text { to } \\
\qquad 25^{\circ} \mathrm{C} \text { ) }\end{array}$ & $23.92 \pm 0.3$ & 99.66 & 1.25 \\
\hline & Postpreparative stability $\left(10^{\circ} \mathrm{C}, 24 \mathrm{~h}\right)$ & $23.98 \pm 0.3$ & 99.91 & 1.25 \\
\hline
\end{tabular}




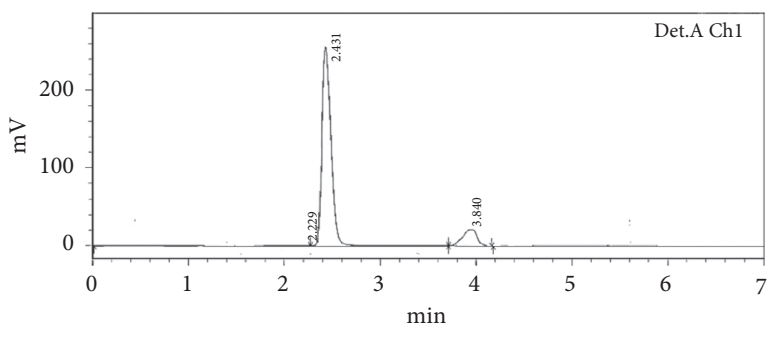

(a)

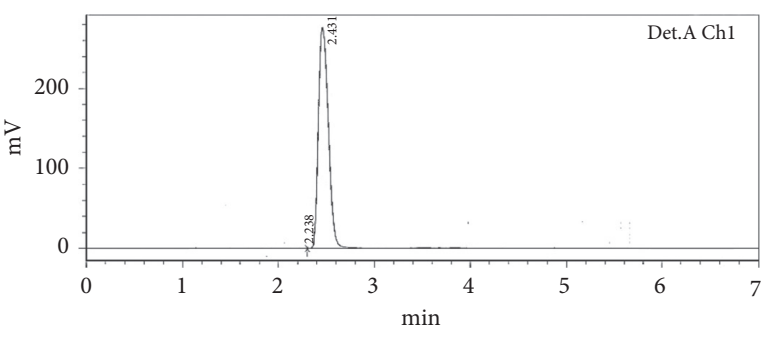

(b)

FIGURE 4: HPLC chromatogram of atorvastatin: (a) acid degradation and (b) base degradation.

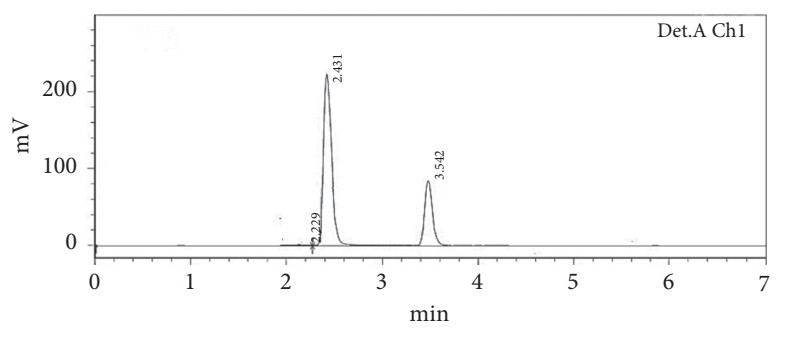

(a)

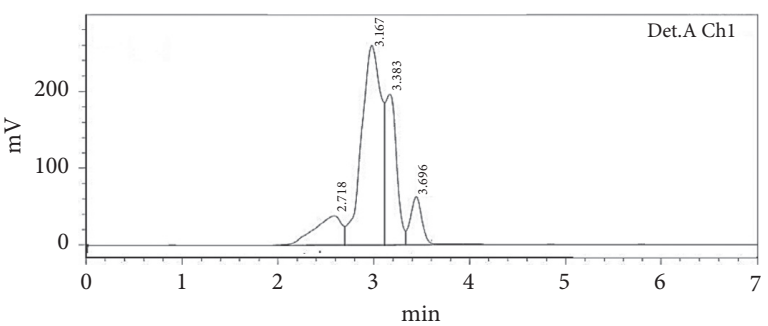

(b)

FIGURE 5: HPLC chromatogram of atorvastatin: (a) oxidative degradation and (b) UV light degradation.

activated from the ground to excited state because it contains the carbonyl and $c=c$ group as well as the formation of free radical takes place [37].

\section{Conclusion}

An analytical quality by design (Box-Behnken) approach was successfully employed for the optimization of the RP-HPLC method. The solvent system (acetonitrile:water, 50:50), flow rate $(0.7 \mathrm{ml} / \mathrm{min})$, and $\mathrm{UV}$ wavelength $(235 \mathrm{~nm})$ were found to be the optimized chromatographic condition for atorvastatin. The developed method was evaluated for the validation, quantification of the quality control sample, and stability study. The method showed a well-resolved chromatographic peak $(\mathrm{Rt}=2.43 \mathrm{~min})$ and found to be accurate and precise. The force degradation study showed well-resolved atorvastatin and degradation product peaks. Our finding suggests that $\mathrm{QbD}$ approaches can be used for the method development and also for the determination of atorvastatin from formulation and pharmacokinetic parameter in vivo.

\section{Data Availability}

The data used to support the findings of this study are included within the article.

\section{Conflicts of Interest}

The author declares that there are no conflicts of interest.

\section{Acknowledgments}

The author is very thankful to Jouf University, Aljouf, KSA, for providing facility to perform this research.

\section{References}

[1] M. H. Moghadasian, "Clinical pharmacology of 3-hydroxy-3methylglutaryl coenzyme A reductase inhibitors," Life Sciences, vol. 65, no. 13, pp. 1329-1337, 1999.

[2] K. D. Tripathi, Essentials of Medical Pharmacology, Jaypee Brothers Medical, New Delhi, India, 6th edition, 2010.

[3] M. Korhonova, A. Doricakova, and Z. Dvorak, "Optical isomers of atorvastatin, rosuvastatin and fluvastatin enantiospecifically activate pregnane $\mathrm{X}$ receptor PXR and induce CYP2A6, CYP2B6 and CYP3A4 in human hepatocytes," PLoS One, vol. 10, no. 9, Article ID e0137720, 2015.

[4] M. S. Rodde, G. T. Divase, T. B. Devkar, and A. R. Tekade, "Solubility and bioavailability enhancement of poorly aqueous soluble atorvastatin: in vitro, ex vivo, and in vivo studies," BioMed Research International, vol. 2014, Article ID 463895, 2014.

[5] Indian Pharmacoeia, Solubilty, 2010.

[6] T. Dongala, N. K. Katari, A. K. Palakurthi, and S. B. Jonnalagadda, "Development and validation of a generic RP-HPLC PDA method for the simultaneous separation and quantification of active ingredients in cold and cough medicines," Biomedical Chromatography, vol. 33, no. 11, Article ID e4641, 2019.

[7] A. Mohammadi, N. Rezanour, D. M. Ansari, B. F. Ghorbani, M. Hashem, and R. B. Walker, "A stability-indicating high performance liquid chromatographic (HPLC) assay for the simultaneous determination of atorvastatin and amlodipine in commercial tablets," Journal of Chromatography. B, Analytical Technologies in the Biomedical and Life Sciences, vol. 846, no. 1-2, pp. 215-221, 2007.

[8] K. R. Naidu, U. N. Kale, and M. S. Shingare, "Stability indicating RP-HPLC method for simultaneous determination of amlodipine and benazepril hydrochloride from their combination drug product," Journal of Pharmaceutical and Biomedical Analysis, vol. 39, no. 1-2, pp. 147-155, 2005. 
[9] S. Ertürk, E. Sevinç Aktaş, L. Ersoy, and S. Fıçıcıoğlu, "An HPLC method for the determination of atorvastatin and its impurities in bulk drug and tablets," Journal of Pharmaceutical and Biomedical Analysis, vol. 33, no. 5, pp. 1017-1023, 2003.

[10] L. Nováková, D. Šatínský, and P. Solich, "HPLC methods for the determination of simvastatin and Atorvastatin," TrAC Trends in Analytical Chemistry, vol. 27, no. 4, pp. 352-367, 2008.

[11] A. F. Martins, C. d. S. Frank, J. Altissimo et al., "Determination of statin drugs in hospital effluent with dispersive liquid-liquid microextraction and quantification by liquid chromatography," Journal of Environmental Science and Health, Part A, vol. 52, no. 10, pp. 939-945, 2017.

[12] A. Zafar, I. El-Bagory, N. K. Alruwaili et al., "Quality by design (QbD) based development and validation of bioanalytical RPHPLC method for dapagliflozin: forced degradation and preclinical pharmacokinetic study," Journal of Liquid Chromatography \& Related Technologies, vol. 43, no. 1-2, pp. 5365, 2020.

[13] M. Qumbar, A. Zafar, S. S. Imam, M. Fazil, and A. Ali, "DOEbased stability indicating RP-HPLC method for determination of lacidipine in niosomal gel in rat: pharmacokinetic determination," Pharmaceutica Analytica Acta, vol. 5, p. 8, 2014.

[14] T. Moolakkadath, M. Aqil, S. S. Imam et al., "Analytical quality by design (AQbD) approach based HPTLC method for quantification of fisetin with superior recovery in formulations," Current Analytical Chemistry, vol. 16, no. 2, pp. 149-157, 2020.

[15] M. V. Krishna, R. N. Dash, B. Jalachandra Reddy, P. Venugopal, P. Sandeep, and G. Madhavi, "Quality by Design (QbD) approach to develop HPLC method for eberconazole nitrate: application oxidative and photolytic degradation kinetics," Journal of Saudi Chemical Society, vol. 20, no. 1, pp. S313-S322, 2016.

[16] S. Karmarkar, X. Yang, R. Garber, A. Szajkovics, and M. Koberda, "Quality by design (QbD) based development and validation of an HPLC method for amiodarone hydrochloride and its impurities in the drug substance," Journal of Pharmaceutical and Biomedical Analysis, vol. 100, pp. 167174, 2014.

[17] E. Rozet, E. Ziemons, R. D. Marini, B. Boulanger, and P. Hubert, "Quality by design compliant analytical method validation," Analytical Chemistry, vol. 84, no. 1, pp. 106-112, 2012.

[18] N. Khorshidi, M. Rahimi, and I. Salimikia, "Application of aeration-assisted homogeneous liquid-liquid microextraction procedure using Box-Behnken design for determination of curcumin by HPLC," Journal of Separation Science, vol. 43, no. 13 , p. $2513,2020$.

[19] P. Nethercote and J. Ermer, "Quality by design for analytical methods: implications for method validation and transfer," Pharmaceutical Technology, vol. 36, pp. 74-79, 2012.

[20] G. Srinubabu, C. A. I. Raju, N. Sarath, P. K. Kumar, and J. V. L. N. S. Rao, "Development and validation of a HPLC method for the determination of voriconazole in pharmaceutical formulation using an experimental design," Talanta, vol. 71, no. 3, pp. 1424-1429, 2007.

[21] A. Jain, S. Beg, S. Saini, T. Sharma, O. P. Katare, and B. Singh, "Application of chemometric approach for QbD-enabled development and validation of an RP-HPLC method for estimation of methotrexate," Journal of Liquid
Chromatography \& Related Technologies, vol. 42, no. 15-16, pp. 502-512, 2019.

[22] M. Mitrovic, A. Protic, A. Malenovic, B. Otasevic, and M. Zecevic, "Analytical quality by design development of an ecologically acceptable enantioselective HPLC method for timolol maleate enantiomeric purity testing on ovomucoid chiral stationary phase," Journal of Pharmaceutical and Biomedical Analysis, vol. 180, p. 113034, 2020.

[23] S. S. Imam, M. Aqil, M. Akhtar, Y. Sultana, and A. Ali, "Optimization of mobile phase by 32-mixture design for the validation and quantification of risperidone in bulk and pharmaceutical formulations using RP-HPLC," Analytical Methods, vol. 6, no. 1, pp. 282-288, 2014.

[24] A. Khan, S. S. Imam, M. Aqil, Y. Sultana, A. Ali, and K. Khan, "Design of experiment based validated stability indicating RPHPLC method of temozolomide in bulk and pharmaceutical dosage forms," Beni-Suef University Journal of Basic and Applied Sciences, vol. 5, no. 4, pp. 402-408, 2016.

[25] S. S. Panda, V. V. Ravi Kumar Bera, S. Beg, and O. Mandal, "Analytical quality by design (AQbD)-Oriented RP-UFLC method for quantification of lansoprazole with superior method robustness," Journal of Liquid Chromatography \& Related Technologies, vol. 40, no. 9, pp. 479-485, 2017.

[26] ICH Topic Q2 (R1), Validation of Analytical Procedures, European Medicines Agency, Amsterdam, Netherlands, 1995.

[27] N. Batrawi, S. Wahdan, and M. Abualhasan, "Analytical method validation of high-performance liquid chromatography and stability-indicating study of medroxyprogesterone acetate intravaginal sponges," Analytical Chemistry Insights, vol. 12, Article ID 1177390117690152, 2017.

[28] N. Khan, Ameeduzzafar, A. Ali, and F. J. Ahmad, "A novel validated stability-indicating HPTLC method to quantitate forskolin as a bulk drug and in a nanosuspension," Indian Journal of Pharmaceutical Sciences, vol. 80, no. 5, pp. 820-826, 2018.

[29] S. Sonawane, S. Jadhav, P. Rahade, S. Chhajed, and S. Kshirsagar, "Development and validation of stability-indicating method for estimation of chlorthalidone in bulk and tablets with the use of experimental design in forced degradation experiments," Scientifica (Cairo), vol. 2016, Article ID 4286482, 2016.

[30] S. Beg, V. Chaudhary, G. Sharma, B. Garg, S. S. Panda, and B. Singh, "QbD-oriented development and validation of a bioanalytical method for nevirapine with enhanced liquidliquid extraction and chromatographic separation," Biomedical Chromatography, vol. 30, no. 6, pp. 818-828, 2016.

[31] U.S. FDA, Guidance for Industry: Analytical Procedures and Methods Validation: Chemistry, Manufacturing and Controls Documentation, USA, U.S. FDA, 2000.

[32] N. Çankaya, İ. Bulduk, and A. M. Çolak, "Extraction, development and validation of HPLC-UV method for rapid and sensitive determination of colchicine from Colchicum autumnale L. Bulbs," Saudi Journal of Biological Sciences, vol. 26, no. 2, pp. 345-351, 2019.

[33] B. T. Alquadeib, "Development and validation of a new HPLC analytical method for the determination of diclofenac in tablets," Saudi Pharmaceutical Journal, vol. 27, no. 1, pp. 66-70, 2019.

[34] R. K. Seshadri, M. M. Desai, T. V. Raghavaraju, D. Krishnan, D. V. Rao, and I. E. Chakravarthy, "Simultaneous quantitative determination of metoprolol, atorvastatin and ramipril in capsules by a validated stability-indicating RP-UPLC method," Scientia Pharmaceutica, vol. 78, no. 4, pp. 821-834, 2010. 
[35] P. Vukkum, J. M. Babu, and R. Muralikrishna, "Stress degradation behavior of atorvastatin calcium and development of suitable stability-indicating LC method for the determination of atorvastatin, its related impurities and its degradation products," Scientia Pharmaceutica, vol. 81, no. 1, pp. 93-114, 2013.

[36] S. Navaratnum, "Photochemical and photophysical methods used in the study of drug photoreactivity," in The Photostability of Drugs and Drug Formulations, H. H. Tonnesen, Ed., pp. 255-284, Taylor \& Francis, London, UK, 2nd edition, 2004.

[37] M. Kracun, A. Kocijan, A. Bastarda, R. Grahek, J. Plavec, and D. Kocjan, "Isolation and structure determination of oxidative degradation products of atorvastatin," Journal of Pharmaceutical and Biomedical Analysis, vol. 50, no. 5, pp. 729-736, 2009. 